Revue européenne des sciences sociales

European Journal of Social Sciences

XLIV-134 | 2006

Quel(s) défi(s) pour les sciences sociales à l'heure de la mondialisation?

\title{
Notice biographique de Gérald Berthoud. Jalons d'une carrière
}

Daniela Cerqui et Mondher Kilani

\section{OpenEdition}

\section{Journals}

Édition électronique

URL : http://journals.openedition.org/ress/278

DOI : $10.4000 /$ ress.278

ISSN : 1663-4446

Éditeur

Librairie Droz

Édition imprimée

Date de publication : 1 juin 2006

Pagination : 19-20

ISBN : 9-782-600-01095-5

ISSN : 0048-8046

Référence électronique

Daniela Cerqui et Mondher Kilani, « Notice biographique de Gérald Berthoud. Jalons d'une carrière » Revue européenne des sciences sociales [En ligne], XLIV-134 | 2006, mis en ligne le 14 octobre 2009, consulté le 10 décembre 2020. URL : http://journals.openedition.org/ress/278 ; DOI : https://doi.org/ $10.4000 /$ ress. 278 


\section{Daniela CERQUI et Mondher KILANI}

\section{NOTICE BIOGRAPHIQUE DE GÉRALD BERTHOUD JALONS D'UNE CARRIÈRE}

Né en 1935, Gérald Berthoud fait des études de Lettres à Neuchâtel avant d'obtenir son Doctorat en ethnologie à Paris. Profondément marqué par la pensée de son directeur de thèse, André Leroi-Gourhan, et plus généralement par l'Ecole française de sociologie à laquelle ce dernier appartient, Gérald Berthoud n'aura de cesse de pratiquer durant toute sa carrière une science sociale rigoureusement fidèle aux principes de ce courant. C'est ainsi qu'en 1988 verra le jour la Revue $d u$ M.A.U.S.S., qu'il fonde en collaboration avec Alain Caillé, et dont il restera membre du comité de rédaction. Elle succède au Bulletin du M.A.U.S.S. qu'ils avaient créé en 1982. Outre le fait qu'il est l'acronyme pour Mouvement AntiUtilitariste en Sciences Sociales, le titre retenu rend indiscutablement hommage à un autre grand penseur de l'Ecole française de sociologie en la personne de Marcel Mauss, dont Gérald Berthoud perpétuera la pensée dans ses enseignements.

A quelques années consacrées à la muséographie - il est assistant conservateur, puis conservateur responsable au Musée d'ethnographie de Genève de 1961 à 1967 - succédera un riche parcours d'enseignant et de chercheur qui le mènera sur divers continents avec des charges de cours aussi bien en Afrique qu'en Amérique. Avant de revenir en Suisse, il restera quelque temps dans le Nouveau Monde - d'abord deux ans comme chercheur à l'Université de Berkeley, puis trois ans comme professeur à celle de Montréal. Nommé professeur extraordinaire d'anthropologie culturelle et sociale à la Faculté des sciences sociales et politiques de l'Université de Lausanne en 1972, puis professeur ordinaire en 1979, il deviendra le directeur de l'Institut d'anthropologie et de sociologie nouvellement créé en 1983 et le restera jusqu'en 1995. Dans le cadre de ce poste, qu'il ne quittera qu'à l'automne 2005 - à l'heure de prendre sa retraite - il sera doyen de la Faculté de 1982 à 1984. Avec son collègue Giovanni Busino, il créera le Groupe d'Etude «Pratiques Sociales et Théories»; ils organiseront alors à un rythme annuel non moins de vingt colloques dont ils assureront aussi l'édition des actes.

Parallèlement, il assurera aussi un enseignement à l'Institut universitaire d'études du développement, à Genève, jusqu'en 1993. Il remplira aussi le rôle de professeur invité pour différentes institutions telles que, pour la Suisse, les Universités de Genève et Fribourg, ou encore l'EHESS à Paris et l'Université de Niamey au Niger, pour ce qui est de l'étranger.

Actif dans différentes hautes instances de politique scientifique, il est nommé au Conseil suisse de la science en 1985. Il y occupera dès 1992, et jusqu'à ce qu'il quitte le Conseil en 1996, un siège de membre du comité directeur du programme «Technology Assessment». Il se consacrera alors plus activement au FNRS pour 
qui, après avoir été membre du comité de direction entre 1995 et 1997, ainsi que du groupe d'experts du programme prioritaire «Demain la Suisse», il devient membre de la division relative à l'évaluation des requêtes dans le domaine des sciences humaines et sociales, et le restera jusqu'en septembre 2005. De par ses connaissances particulièrement larges, Gérald Berthoud y sera aussi appelé à évaluer de nombreux projets interdiciplinaires faisant intervenir des disciplines très différentes, telles que l'architecture, l'urbanisme ou l'écologie. Il représentera en outre le FNRS au Comité permanent des sciences sociales de la Fondation Européenne de la Science (European Science Foundation) et sera membre du comité de l'Académie suisse des sciences humaines de 1996 à 1999. Gérald Berthoud est enfin l'auteur de plusieurs ouvrages et de très nombreux articles scientifiques parus dans des revues prestigieuses de renommée internationale. 